\title{
Заключение
}

На основе решения задачи переноса газовой среды в круговом термохимическом реакторе проточного типа с разложением диборана на нагретой поверхности углеродных волокон предложена методика определения кинетических параметров его разложения.

Литература:

1. Франк-Каменецкий Д.А. Диффузия и теплопередача в химической кинетике. - М. : Наука, 1967. - 491 с.

Статья отправлена: 06.06.2017 г.

(c) Скачов В.А., Иванов В.В., Нестеренко Т.Н., Моснйко Ю.В.

\section{ЦИТ: иа217-074}

DOI: 10.21893/2415-7538.2017-06-1-074

\section{УДК 621.83}

Карабань В.Г., Жук Д.Н., Колесов М.А.

ИССЛЕДОВАНИЕ КОНТАКТНЫХ ПОВЕРХНОСТЕЙ МЕХАНИЗМА СВОБОДНОГО ХОДА

Волгоградский государственный технический университет, Волгоград, пр. Ленина, 28, 400005

Karaban V.G., Dguk D.N., Kolesov M.A. THE RESEARCH OF SURFACE OF WEDGE BODIES OF FREEWHEELING MECHANISMS

Volgograd State Technical University, Volgograd, Lenin avenue, 28, 400005

Аннотация. В работе исследуется рельеф поверхностей клинового тела механизма свободного хода. Выделяется относительная опорная поверхность. Полученные с помощью сканирующего зондового микроскопа результать позволяют корректировать прогнозируемые параметры износа клинового тела и учитывать влияние высотных показателей качества поверхностей при проектировании механизмов.

Ключевые слова: качество поверхности, клиновой механизм свободного хода, клин, микронеровности, рельеф поверхности, относительная опорная поверхность.

Abstract. In this paper we research the relief of surfaces of wedge bodies of freewheeling mechanisms. Mark out relative area of bearing. The results obtained by scanning probe microscope let us correct predicted deterioration parameters of a wedge body and consider the effect of surfaces' altitude quality indicators while designing mechanisms.

Key words: a wedge freewheeling mechanism, wedge, roughness, relief of surface, relative area of bearing.

Бесступенчатые механические передачи находят широкое применение в автоматических и ручных трансмиссиях, приводах машин. Их бурное развитие, в значительной степени, связано с появлением новых конструкционных материалов, смазочных материалов, технологий и новых возможностей при 
исследовании рабочих процессов. К бесступенчатым передачам относят и механические импульсные, в состав которых входят наиболее ответственные узлы, полностью или частично использующие фрикционные контактные поверхности при работе - механизмы свободного хода(MCX). В работе рассматриваются рабочие поверхности клинового МСX конструкции А.А. Благонравова[1]. Ряд аспектов работы механизма рассмотрены в [2]. Рациональное проектирование механизма с заданными свойствами и долговечностью зависит от площади контакта нагруженных элементов при работе и ее изменении с течением времени при износе. Важное значение имеют «карманы» в которых может размещаться смазка. Ряд ответов на вопросы о контактирующих поверхностях и их изменений может дать исследование рельефа контактных поверхностей клина $\mathrm{MCX}$, результаты которого приводятся в работе.

Рассматриваемый клин был изготовлен из фрикционного композиционного материала на основе железа и меди. Измерение показателей рельефа осуществлялось с помощью сканирующего зондового микроскопа Solver P47H.

По характеристикам микроскопа была рассчитана расширенная неопределенность, которая при вероятности 95\% составила 230 нм. При оценке качества измерений с использованием сканирующего зондового микроскопа Solver P47Н вероятность неправильного решения составляла 1\%. Показатели рельефа рассматривались в соответствии ГОСТ Р ИСО 25178-2-2014.

Был проведен анализ изменения контактной поверхности при возможном износе и деформации. Косвенно это изменение может быть получено как изменение площади поверхности, отсекаемой плоскостью эквидистантной средней плоскости на заданном уровне сечения, который отсчитывается от максимального выступа рельефа. Такую поверхность будем называть опорной. На рис. 1 показано сечение на уровне 40\% от максимальной высоты.

На рис. 2 плоскость сечения 40\% от высоты. Соотношение общей площади участка и опорной поверхности составило около 12\%. На рис.2 участки опорной поверхности представлены темным цветом. Максимальная высота составляла 2,7 мкм, уровень сечения 1,1мкм. Для уровня сечения 50\%(1,35 мкм), опорная площадь составила 44\%.

На рис. 3 показана зависимость относительной опорной поверхности для наружной и внутренней поверхностей клинового тела в зависимости от уровня сечения, в процентах от максимальной высоты.

Ранее были получены зависимости износа клинового тела от длительности работы[3]. Используя указанные результаты можно определить опорную поверхность для заданного ресурса. Например, для 400 часов работы опорная поверхность на наружной части клина составит около 45\%.

Таким образом, имеется возможность корректировать данные при расчетах напряженно - деформированного состояния, что повысит надежность получаемых данных при проектировании. Создавать рациональный рельеф, в том числе и регулярный, с точки зрения контактной поверхности и размещения смазки. Зная контактную поверхность, можно регулировать ее свойства в зависимости от необходимого ресурса при заданной нагрузочной способности. 


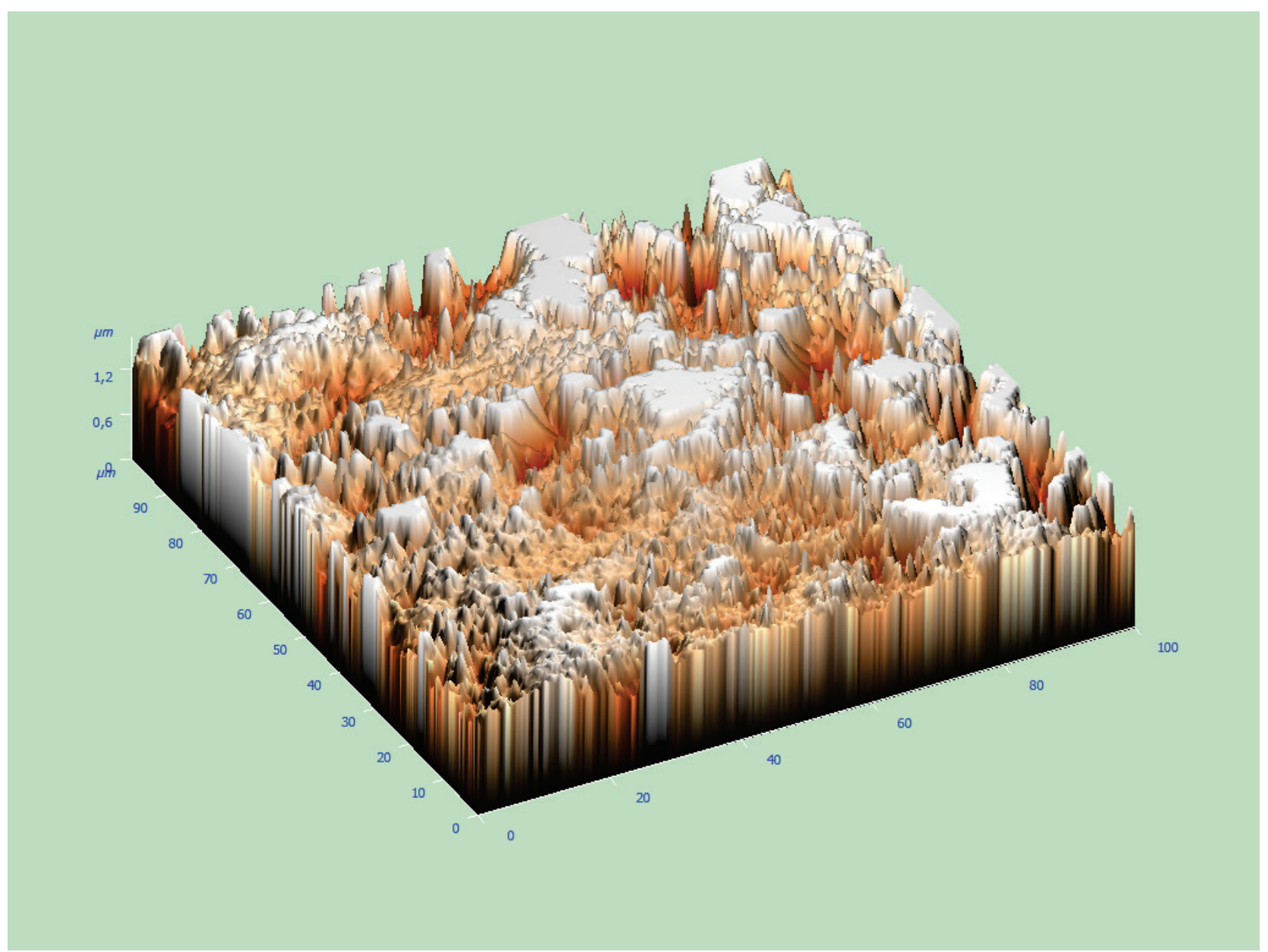

Рис. 1 Сечение плоскостью на уровне 40\% от высоты.

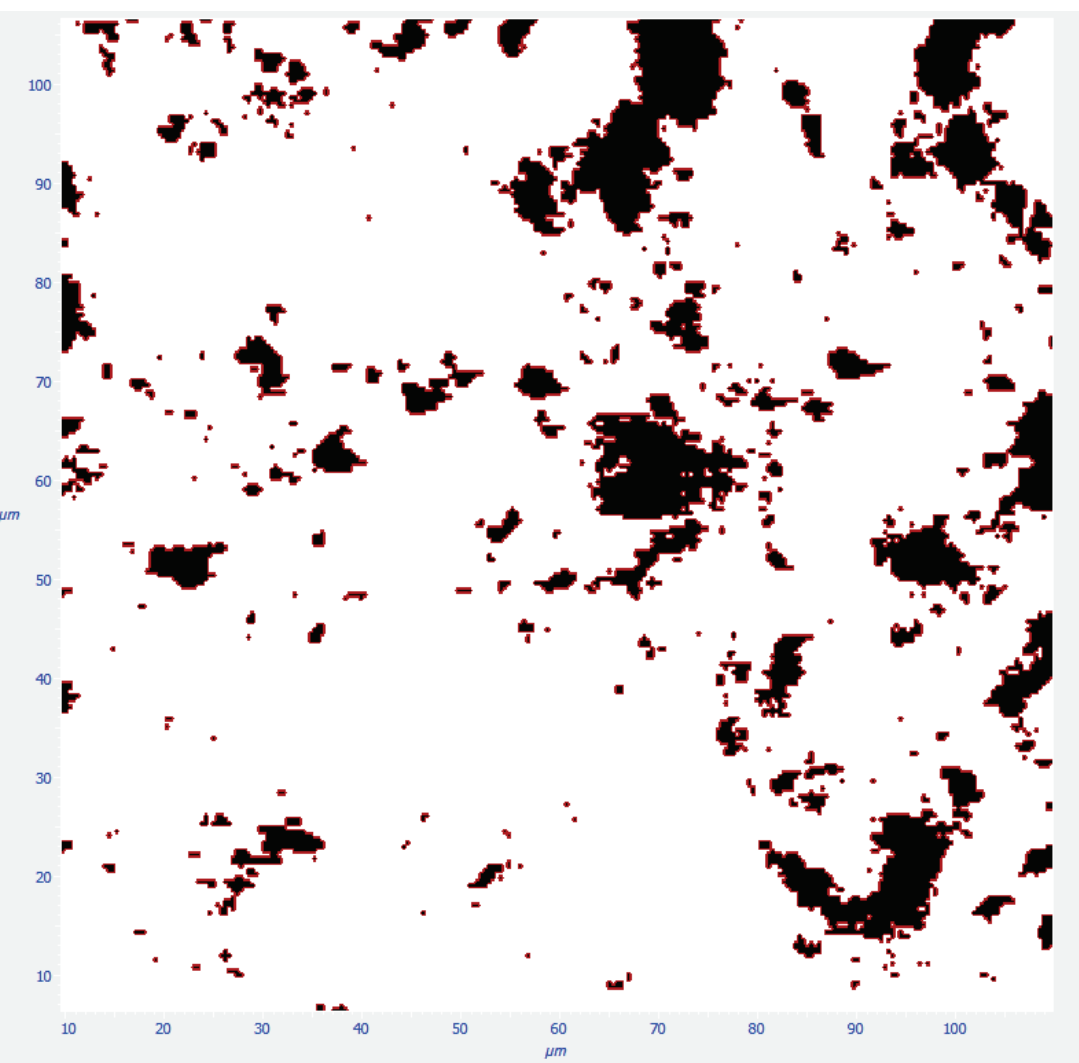

Рис. 2 Плоскость сечения на уровне 40\% от высоты. 


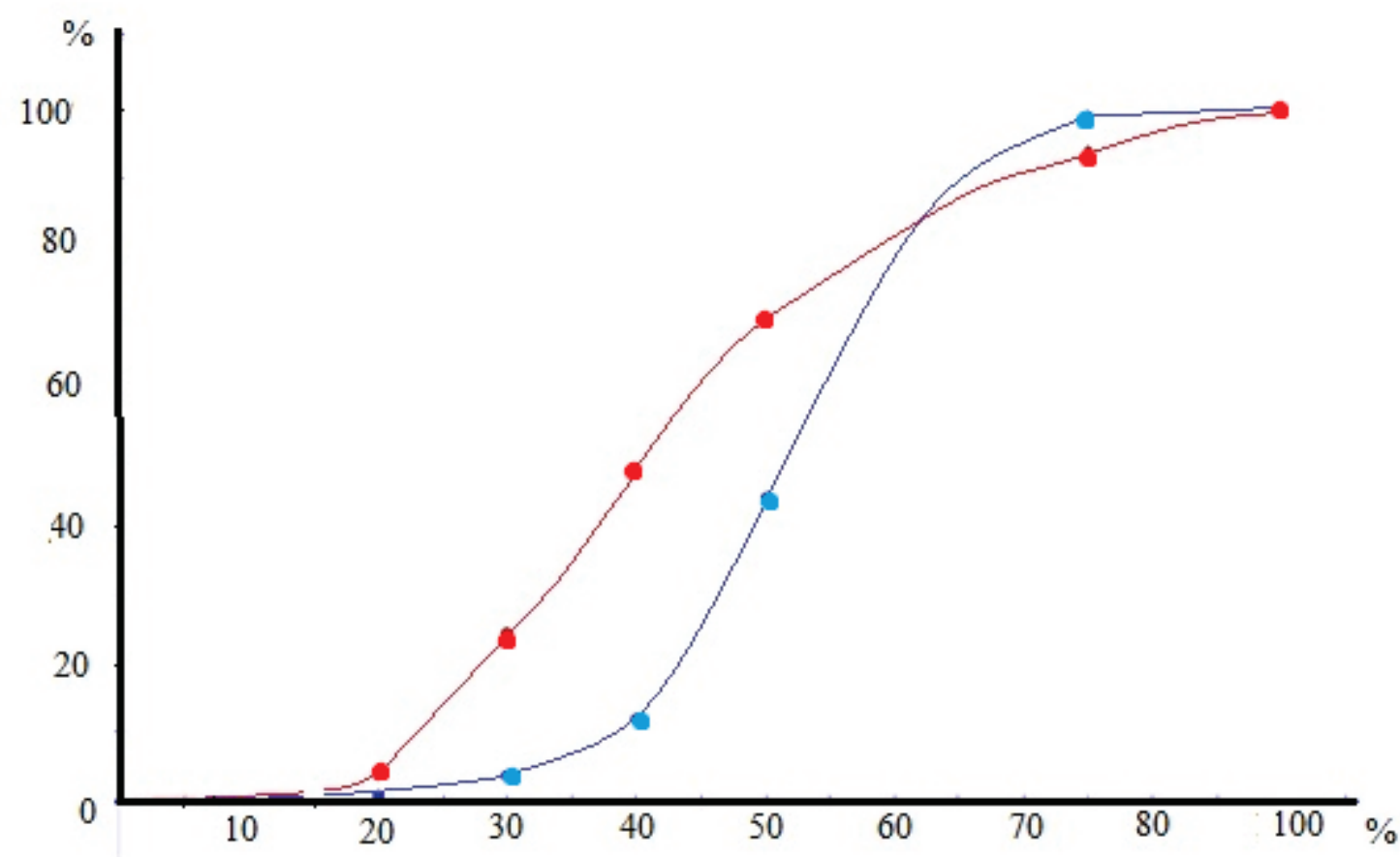

Рис. 3 Зависимость относительной опорной поверхности для наружной и внутренней частей клинового тела от уровня сечения.

Литература:

1. Благонравов А.А. Бесступенчатые импульсные передачи/А.А. Благонравов.-М.: Машиностроение, 2005.- 366с.

2. Карабань, В.Г. Основные результаты исследования влияния микрорельефа и материалов контактных поверхностей на обеспечение качества включения клиновых механизмов свободного хода / Карабань В.Г., Шипицына A.А. // Сборник научных трудов SWorld. - 2014. - Вып. 4, том 6. - С. 86-89.

3. Карабань, В.Г. Исследование качества поверхности клиновых тел механизмов свободного хода после приработки / Карабань В.Г., Шипицына А.А. // Сборник научных трудов SWorld. - 2014. - Вып. 2, т. 2. - С. 48-52.

ЦИТ: иа217-014

DOI: 10.21893/2415-7538.2017-06-1-014

УДК 534-18

ОГЛЯД МОЖЛИВИХ ЗАСТОСУВАНЬ АКУСТИЧНИХ МЕТАМАТЕРІАЛІВ

Національний технічний університет Украйни «Київський політехнічний інститут» ім. Ігоря Сікорського,

Киї, проспект Перемоги, 37, 03056

AUTOMATION OF THE CALCULATION PROGRAMS

Kopytko J. S.

National technical university of Ukraine "Kyiv polytechnic institute" named after

Igor Sikorskiy,

Kyiv, Peremogy avenue 37, 03056 